\title{
Changes in Orthopedic Services in Two Indonesian Tertiary-referral Hospitals during the Coronavirus-19 Pandemic
}

\author{
Sholahuddin Rhatomy ${ }^{1 *}$, Krisna Yuarno Phatama ${ }^{2}$, Faiz Alam Rasyid ${ }^{3}$, Edi Mustamsir $^{2}$ \\ ${ }^{1}$ Department of Orthopaedics and Traumatology, Dr Soeradji Tirtonegoro General Hospital, Faculty Of Medicine, Public Health \\ and Nursing, Universitas Gadjah Mada, Yogyakarta, Indonesia; ${ }^{2}$ Department of Orthopaedics and Traumatology, Dr Saiful \\ Anwar General Hospital, Faculty of Medicine, Brawijaya University, Malang, Indonesia; ${ }^{3}$ Soeradji Tirtonegoro Sport Center and \\ Research Unit, Dr Soeradji Tirtonegoro General Hospital, Klaten, Indonesia
}

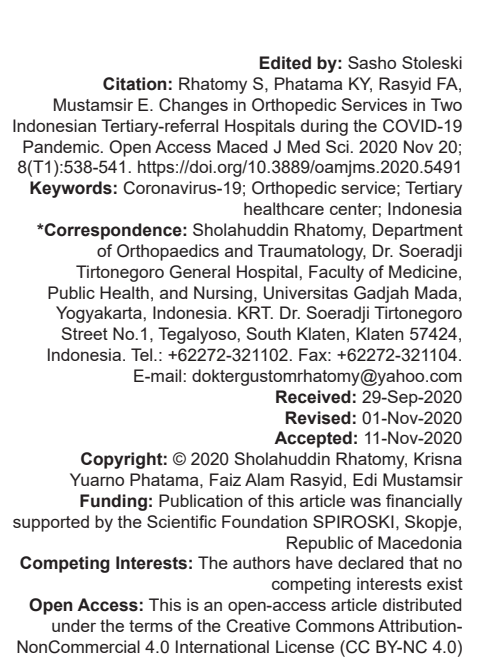

\section{Abstract}

BACKGROUND: Many countries report decreasing on the number of hospital visit even on the emergency cases.

AIM: This study aims to reveal the important data on how big the impact of coronavirus-19 pandemic on orthopedic services in two Government's tertiary-referral hospitals.

METHODS: This research is a comparison study to measure the trend of orthopedic services, the monthly orthopedic surgical load and outpatient visit were examined during the period of March to May 2020 (the early pandemic period) then compared to the same period in the 2019

RESULTS: The lowest number of outpatient visits occurred during May 2020 with 715 total number of outpatient visit. The lowest number of orthopedic surgery occurred during May 2020 with 167 total number of orthopedic surgery. Significant decrease of outpatient visits is recorded in 3 months of early pandemic period compared to the same period in 2019 ( $p$ < 0.005). Regarding the orthopedic surgical loads, the data show significant decrease in number of orthopedic surgeries in early pandemic period compared to those months in $2019(p<0.005)$. The largest declines were in visits for post-operative control patient $(-179)$, spinal problem $(-127,33)$, and osteoarthritis $(-91,33)$.

CONCLUSION: There was a significant difference in outpatient visit and orthopedic surgery number in the early pandemic period compared to the period before the pandemic occur.

The largest drops in outpatient visit were in visits for post-operative control patient and spinal problem.

\section{Introduction}

Coronavirus disease (COVID-19) is an emerging infectious disease caused by severe acute respiratory syndrome coronavirus 2 (SARS-COV2). Coronaviruses have a history of causing public health threats in the past; they previously caused outbreaks of SARS in China and Middle East respiratory syndrome in Saudi Arabia. The first case of COVID-19 was confirmed in December 2019 in Wuhan, China [1]. COVID-19 is a respiratory pathogen with the most common symptoms being common cold-like syndrome, fever, dry cough, shortness of breath, and SARS in severe cases. The less common symptoms are productive cough and gastrointestinal problems [2]. In early March 2020, the WHO declared COVID-19 a pandemic. Later in March, the president of Indonesia signed the Government Regulation Number 21/2020 to exercise the large-scale social restriction approach to control the spread of the disease. Non-essential activities were restricted, and only essential public places were allowed to remain open, such as grocery shops, gas stations, pharmacy shops, and hospitals. The measures undertaken in Indonesia were less rigid than those undertaken in China, the epicenter of the disease, where extreme measures were implemented, including a lockdown [3].

Dr. Soeradji Tirtonergoro Central General Hospital and Dr. Saiful Anwar General Hospital, which are located in Central Java and East Java Province, respectively, are categorized as type $A$ hospitals in Indonesia, which are designated as tertiary referral hospitals by the Government of Indonesia provide healthcare for up to 70,000 people annually. The orthopedics and traumatology department in the hospitals provides subspecialty services, such as adult reconstruction, sport, hand and microsurgery, spine surgery, pediatric orthopedic, and musculoskeletal oncology, along with advance musculoskeletal trauma service.

Since the COVID-19 outbreak, many countries have reported decreasing numbers of hospital visits [4] The Austrian, Chinese, and Italian health centers report 
downward trends in the number of hospital visits, even in emergency cases [5], [6], [7]. Moreover, US centers have reported that emergency department visits dropped more than $50 \%$ during this pandemic [8].

This study aimed to reveal important data highlighting the impact of the COVID-19 pandemic on orthopedic services in two Government's tertiary referral hospitals. The study results can be valuable to health policy makers during this pandemic.

\section{Materials and Methods}

To evaluate the trend of orthopedic services, the monthly orthopedic surgical load and outpatient visits were examined during the period from March to May 2020 (the early pandemic period), in comparison with the same period in 2019 and analyzed separately.

The change in mean visits per month between the early pandemic period and the respective period from the previous year was calculated as the mean difference in total visits for a diagnostic category between the two periods, divided by 3 months. The visit prevalence ratio was calculated for each diagnostic category as the proportion of outpatient visits during the early pandemic period divided by the proportion of visits during the prior year. The same method is used for the analysis of differences in the number of orthopedic surgeries.

Statistical data were analyzed using an independent sample t-test. The analyses were performed using the Statistical Package for the Social Sciences (SPSS) for Windows version 25.0, manufactured by IBM in New York USA. The results of the difference between the number of outpatient visits between the two groups were considered statistically significant if $p<0.05$. The same method was used to analyze the differences in the number of orthopedic surgeries.

\section{Results}

Data taken from Dr Soeradji Tirtonergoro Central General Hospital (Hospital X) and Dr Saiful Anwar General Hospital (Hospital Y) were analyzed.

The average monthly number of outpatient visits in those two hospitals during the early pandemic period was 1181 visits per month, compared to the 1972 visits during the period in comparison. The lowest number of outpatient visits occurred during May 2020 with 715 total outpatient visits. The monthly number of outpatient visits is shown in Figure 1.

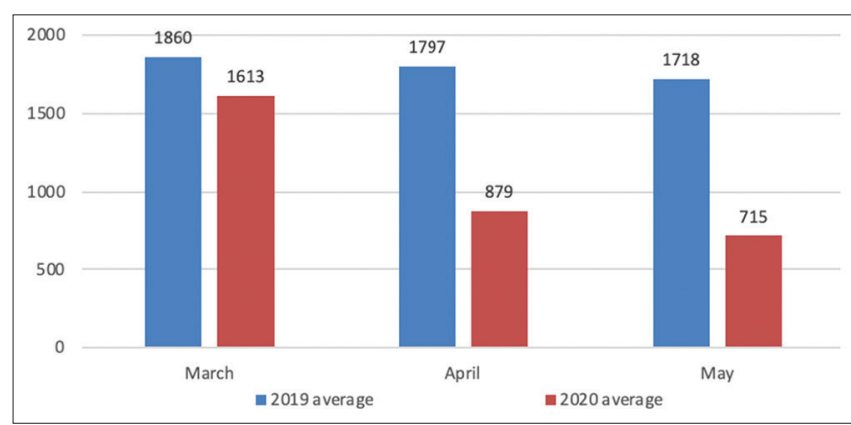

Figure 1: Outpatient Visit Number

The monthly orthopedic surgical loads also decreased. From the data collected, there were 221 surgeries per month in 2020, compared to 362 per month 1 year prior in those two hospitals. The lowest number of orthopedic surgeries occurred during May 2020 is 167 . The monthly number of orthopedic surgeries is shown in Figure 2.

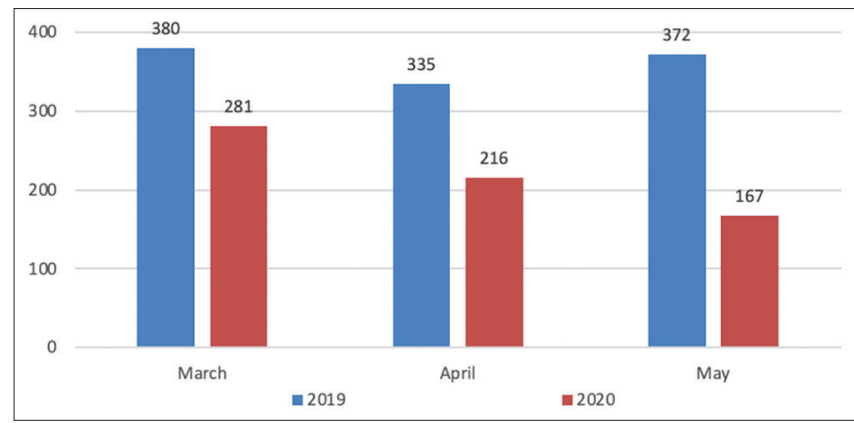

Figure 2: Orthopaedic Surgery Number

A significant decrease in outpatient visits was recorded in the 3 months of the early pandemic period compared to the same period in 2019 ( $p<0.005$ ), as shown in Table 1.

Table 1: Outpatient number

\begin{tabular}{llll}
\hline Month & Year & Outpatient number & p value \\
\hline March & 2019 & 1860 & 0.000 \\
\multirow{2}{*}{ April } & 2020 & 1613 & \\
& 2019 & 1797 & 0.000 \\
May & 2020 & 879 & 0.000 \\
& 2019 & 1718 & \\
\hline
\end{tabular}

Regarding the orthopedic surgical loads, the data showed a significant decrease in the number of orthopedic surgeries in March, April, and May 2020 (early pandemic period) compared to those months in 2019 ( $p<0.005)$, as shown in Table 2.

Table 2: Orthopedic surgery number

\begin{tabular}{llll}
\hline Month & Year & Patients & p value \\
\hline March & 2019 & 380 & 0.014 \\
\multirow{3}{*}{ April } & 2020 & 281 & \\
& 2019 & 335 & 0.000 \\
May & 2020 & 216 & \\
& 2019 & 372 & 0.000 \\
\hline
\end{tabular}

The largest declines were in visits for postoperative control patients $(-179)$, spinal problems $(-127,33)$, and osteoarthritis $(-91,33)$. In terms of the number of monthly orthopedic surgeries, spine surgery, and fracture/dislocation surgery have the biggest decline with $(-20)$ change in mean number (Tables 3 and 4 ). 
Table 3: Differences in mean monthly numbers of outpatient visits for diagnostic categories

\begin{tabular}{lll}
\hline Diagnostic category & $\begin{array}{l}\text { Change in mean no of } \\
\text { monthly outpatient visits }\end{array}$ & $\begin{array}{l}\text { Prevalence ratio } \\
(95 \% \mathrm{Cl})\end{array}$ \\
\hline Post-operative control & -179 & 1.16 \\
Spinal problem & -127.33 & 0.67 \\
Osteoarthritis & -91.33 & 0.78 \\
Sport & -24 & 0.78 \\
Other arthritis & $-16,33$ & 0,92 \\
Fracture (Trauma) & $-13,66$ & 1.05 \\
Arthroplasty & -10.33 & 1.41 \\
Nerve/muscle problem & -6 & 0.99 \\
Others & -4.66 & 0.007 \\
Neoplasm & -4.33 & 0.007 \\
Dislocation & $-4,33$ & 0.86 \\
Congenital/acquired deformity of the limbs & -4.33 & 1.13 \\
Bone/joint infection & -3.66 & 1.15 \\
Open wound & -1 & 0.43 \\
\hline
\end{tabular}

\section{Discussion}

Our findings show that during the early 3 months interval in the COVID-19 pandemic, there was a significant decrease in outpatient visits in each month compared to outpatient visits during the comparison period $(p<0.05)$. Furthermore, our data revealed that orthopedic surgical loads decreased significantly in March, April, and May 2020 (early pandemic period) compared to those periods a year before $(p>0.05)$.

Table 4: Differences in mean monthly numbers of orthopedic surgery

\begin{tabular}{lll}
\hline Surgery & $\begin{array}{l}\text { Change in mean no of monthly } \\
\text { average orthopedic surgery numbers }\end{array}$ & $\begin{array}{l}\text { Prevalence } \\
\text { ratio }(95 \% \mathrm{Cl})\end{array}$ \\
\hline Spine & -20 & 0.35 \\
Fracture/Dislocation (Trauma) & -20 & 1.11 \\
Sport & -5.66 & 0.71 \\
Arthroplasty/Adult Reconstruction & -2.66 & 1.01 \\
Neoplasm & -0.33 & 0.66 \\
Nerve Procedure & -0.33 & 0.66 \\
Infection & 0.33 & 1.40 \\
Congenital Abnormality & 0 & 1.36 \\
Others & 2.66 & 1.94 \\
\hline
\end{tabular}

Our findings are similar to those of an Austrian study conducted by Metzler et al [6]. who reported that there had been a significant decline in hospital patient admissions in Austria since the outbreak of COVID19. A study in Hong Kong by Tam et al [7]. supports this finding with the same conclusion that there is a significant decrease in the number of visits in the emergency department compared to the same period in the year before, even in emergency and life-threatening situations such as acute coronary syndrome.

Another study that supports our findings is the paper by Lazzerini et al [5]. in Italy that reports a significant decrease in the number of visits to pediatric emergency departments, even in acute infection and trauma cases.

A US center study by Hartnett et al [4]. and Wong et al [8]. also reported a decrease in the number of visits to the emergency department that reached $50 \%$ drop nationwide.

A study from England by Thornton [9] reports that there is a $25 \%$ decrease in emergency department visits during the COVID-19 pandemic. On the other hand, only pneumonia cases increased in number since the lockdown due to the COVID-19 pandemic began.
Significant differences in the number of outpatient visits and orthopedic surgeries may be due to some of the following reasons. First, the government regulation that exercised the large-scale social restriction was just signed by the president in March 2020. The non-essential activities were restricted, and only essential services were excluded, such as grocery, gas station, pharmacy, and hospital. Other activities, such as school, concert, and other public crowds, were prohibited.

Another factor that may be a cause of the decreasing number of outpatient visits and surgery loads is the appeal by the Indonesian Orthopaedic Association in response to large-scale social restrictions by the government. They urged the patients to postpone their visits to the orthopedist or hospital unless there was an emergency situation such as fracture, either open or closed, joint dislocation, and bone or joint infection that is marked by joint swelling and fever, severe pain that did not subside with analgesics, sudden motor, or sensory loss in a limb that is accompanied by bladder or bowel incontinence following any fall or injury, and post-operative control patient.

Future studies will help to make further statements about the proportion of the decline in outpatient visits and orthopedic surgery that were not preventable or avoidable, such as those for limbthreatening or life-threatening conditions, those that could be managed at primary care, and those that need regular observation for special conditions.

The findings in this report are subject to some limitations. First, the diagnosis is based on the specific code in the hospital, which may limit the variability of the diagnosis and may differ from other hospitals. Later, more than two center studies may be needed to enhance the quality and strength of the study and to enrich the data variability.

The strength of this study is that it used primary data sources, and the hospitals where the study was taken are the highest referral hospitals for COVID-19 patients.

\section{Conclusion}

There was a significant difference in the number of outpatient visits and orthopedic surgeries in the early pandemic period compared to the period before the pandemic occurred.

The largest drops in outpatient visits were in visits for post-operative control patients and spinal problems. In terms of the number of monthly spine surgeries and trauma surgery have the biggest decline in mean number. 


\section{Acknowledgments}

We thank Riky Setyawan for his help during the manuscript preparation.

\section{Authors' Contribution}

Sholahuddin Rhatomy and Faiz Alam Rasyid conceived the study, collected the data, analyzed data. Sholahuddin Rhatomy prepared and drafted the manuscript. KrisnaYuarno Phatama edited manuscript. Edi Mustamsir visualized the data into table and graph. Sholahuddin Rhatomy and Faiz Alam Rasyid reviewed and revised the manuscript.

\section{References}

1. Rothan HA, Byrareddy SN. The epidemiology and pathogenesis of coronavirus disease (COVID-19) outbreak. J Autoimmun 2020;109:102433. https://doi.org/10.1016/j.jaut.2020.102433 PMid:32113704

2. Bahl P, Doolan C, de Silva C, Chughtai AA, Bourouiba L, MacIntyre CR. Airborne or droplet precautions for health workers treating coronavirus disease 2019? J Infect Dis 2020;1:189. https://doi.org/10.1093/infdis/jiaa189

PMid:32301491

3. MacIntyre CR. Global spread of COVID-19 and pandemic potential. Glob Biosecur 2020;1:55.

4. Hartnett KP, Kite-Powell A, DeVies J, Coletta MA, Boehmer TK, Adjemian $\mathrm{J}$, et al. Impact of the COVID-19 pandemic on emergency department visits United States, January 1, 2019May 30, 2020. MMWR Morb Mortal Wkly Rep 2020;69(23):699704. https://doi.org/10.15585/mmwr.mm6923e1 PMid:32525856

5. Lazzerini M, Barbi E, ApicellaA, Marchetti F, Cardinale F, Trobia G. Delayed access or provision of care in Italy resulting from fear of COVID-19. Lancet Child Adolesc Health 2020;4(5):e10-1. https://doi.org/10.1016/s2352-4642(20)30108-5 PMid:32278365

6. Metzler B, Siostrzonek P, Binder RK, Bauer A, Reinstadler SJ. Decline of acute coronary syndrome admissions in Austria since the outbreak of COVID-19: the pandemic response causes cardiac collateral damage. Eur Heart J 2020;41(19):1852-3. https://doi.org/10.1093/eurheartj/ehaa314

PMid:32297932

7. Tam CF, Cheung KS, Lam S, Wong A, Yung A, Sze M, et al. Impact of coronavirus disease 2019 (COVID-19) outbreak on st-segment-elevation myocardial infarction care in Hong Kong, China. Circ Cardiovasc Qual Outcomes 2020;13(4):e006631. https://doi.org/10.1161/circoutcomes.120.006631

8. Wong LE, Hawkins JE, Langness $S$, Murrell $\mathrm{KL}$, Iris $\mathrm{P}$ Sammann A. Where are all the patients? Addressing Covid19 Fear to Encourage Sick Patients to Seek Emergency Care. NEJM Catalyst Innovations in Care Delivery; 2020. p. 3.

9. Thornton J. Covid-19: A\&E visits in England fall by $25 \%$ in week after lockdown. BMJ 2020;369:m1401. https://doi.org/10.1136/ bmj.m1401

PMid:32253175 